\title{
Estudo da estrutura do treino de jovens mesatenistas dos Centros de Treino da Federação Portuguesa de Ténis de Mesa
}

\author{
Fernando Malheiro
}

https://doi.org/10.5628/rpcd.05.02.184

\author{
Director Técnico da \\ Federação Portuguesa de Ténis de Mesa
}

\section{RESUMO}

Conhecer o processo de treino realizado nos centros de treino da Federação Portuguesa de Ténis de Mesa é o objectivo deste estudo. A caracterização das metodologias adoptadas na preparação dos jovens jogadores e a sua comparação com os modelos de referência permitirão avaliar até que ponto as estratégias seguidas promovem um harmonioso desenvolvimento da formação desportiva dos mais jovens, por forma a possibilitar as melhores performances na idade adulta. O desenho metodológico escolhido é de carácter exploratório-descritivo (2). A técnica de pesquisa adoptada foi a análise documental, que nos permitiu caracterizar a estrutura e os conteúdos do treino a partir de documentos não elaborados especificamente para fins de investigação. Os documentos analisados foram os dossiers de treino - 739 unidades de treino, correspondentes a 1641 horas de treino - dos três centros de treino (CT) da Federação Portuguesa de Ténis de Mesa, relativos à época de 2002/2003. Esses documentos constituíam os programas de preparação de 32 crianças e jovens mesatenistas com idades no intervalo 10 a 15 anos: 11 no CT de Bragança, 15 no CT do Porto e 6 no CT da Madeira. Os resultados deste estudo evidenciam que: (i) os valores registados quanto ao volume anual de treino parecem não ser suficientes para a obtenção das melhores performances na idade adulta; (ii) é perceptível que os treinadores valorizam o treino técnico e o treino táctico, em detrimento de outras componentes do treino; (iii) de entre as capacidades motoras, são as formas de manifestação da velocidade - velocidade de reacção e velocidade nos deslocamentos - que são objecto de uma maior atenção; (iv) é notória a lacuna no treino da componente psicológica. Numa análise mais detalhada dentro de cada categoria, é possível concluir que o treino de algumas das subcategorias definidas - no Treino Técnico: "Serviço",

"Deslocamentos em Profundidade", "Precisão" e

"Adaptabilidade"; no Treino Táctico: "Contra a Tomada de Iniciativa"; e no Treino Psicológico: "Concentração" e "Atenção" - não está de acordo com a sua importância no ténis de mesa moderno.

Palavras-chave: alto rendimento, crianças e jovens, ténis de mesa, treino desportivo.

\begin{abstract}
Training programme evaluation of young tennis players participating in the Portuguese Table Tennis Federation training centers

The purpose of the present study was to understand the training process in 32 children and adolescents table tennis players aged 10-15 years following a special training programme in three training centers of the Table Tennis Portuguese Federation. This will help to identify the right methodology to be used, that is to say, the identification of the adopted methodology will enable to verify if long term formation process used will help to improve significantly young players' performance in adult age. Documental analysis approach was utilized in order to assess the training dossiers of the 2002/03 season. During this season the young player of the three training centers had 739 training sessions which were equal to 1641 practice hours. Results revealed that: i) The annual training volume was not enough to bring about improvement of the young tennis players in adult age; ii) Coaches did not pay attention to the importance of the psychological aspect. Rather, they emphasized technical, tactical and speed aspects. We concluded, that there is a need to shift given emphasis to other training categories.
\end{abstract}

Key Words: performance, children and adolescents, table tennis, sports training. 


\section{INTRODUÇÃOO}

Em Portugal, o número de atletas de ténis de mesa tem aumentado e o nível qualitativo tem melhorado significativamente, como demonstram os resultados internacionais mais recentes. Em 1994 o número de atletas federados aumentou de cerca de 2000 para 5000 atletas. Desde então esses números têm-se mantido estabilizados.

Em Paris, nos Campeonatos da Europa de Jovens 1996, pela primeira vez na longa história do ténis de mesa português, um atleta ganhou uma medalha de bronze numa prova individual. Nos dois anos seguintes os jovens portugueses continuaram a ganhar medalhas e a vencer torneios internacionais, bem como a instalar-se no top 5 e top 10 europeus. Nos últimos quatro anos (2000 - 2003), nos Campeonatos da Europa de Jovens, Encontro Mundial de Juniores e top 12 Europeu, assistimos a um conjunto de resultados de elevado nível, consubstanciados na conquista de 3 medalhas de ouro, 3 medalhas de prata e 6 medalhas de bronze.

Se tomarmos como referência a década de 90 e o início dos anos 2000, e considerarmos este momento como aquele em que o ténis de mesa português atingiu nas classes jovens resultados de alto nível europeu, verificamos, passados estes anos, que os resultados dos seniores estão muito longe dos alcançados em jovens.

No contexto do ténis de mesa português parece pertinente ir mais atrás e começar por analisar a forma como se está a fazer a formação das crianças e jovens portugueses, pois não devemos excluir a possibilidade dos sinais de descontinuidade de resultados na classe de seniores terem origem já nesta fase. O propósito deste estudo é, pois, o de descrever, analisar e compreender o processo de preparação desenvolvido nos centros de treino da Federação Portuguesa de Ténis de Mesa e verificar se as estratégias adoptadas promovem o desenvolvimento harmonioso das crianças, de forma a possibilitar as melhores performances na idade adulta.

\section{CARACTERÍSTICAS DO JOGO, HOJE}

O aparecimento da cola rápida, a utilização de materiais que proporcionam grande velocidade e aderência e a intenção táctica de jogar muito próximo do ressalto, fizeram com que o jogo atingisse um ritmo muito elevado. Estes factos tiveram consequências nas características do jogo (17): (i) O ténis de mesa moderno está cada vez mais rápido e dinâmico; (ii) As jogadas são finalizadas entre 2 a 4 golpes, utilizando, fundamentalmente, topspins com muita rotação e fortes golpes terminais; (iii) $\mathrm{O}$ aumento da velocidade do jogo implicou a diminuição do tempo de cada jogada; (iv) O tempo médio das fases activas do jogo é de 3,6 segundos e o tempo médio de inactividade é de 9,41 segundos.

Ouyang e Wu (18) expressam também a importância de uma técnica completa, que descrevem como a capacidade de jogar em tempos diferentes, com forças diferentes, de usar diferentes partes do corpo (dedos, pulso, antebraço, braço, cintura, anca e pernas), e de ser capaz de coordenar e dar ênfase a cada uma delas. Paralelamente, mencionam como factores prioritários para ganhar o ponto a capacidade de assumir riscos, ao mesmo tempo que reforçam a importância da eficácia nas três primeiras bolas, de possuir uma boa capacidade de deslocamento e de um bom equilíbrio do jogo dos dois lados (direita e esquerda).

\section{CARACTERIZAÇÃO DA ACTIVIDADE}

O facto do ténis de mesa ser um desporto de duelo, gerando uma situação de confronto no qual se opõem dois adversários cujos interesses são diametralmente opostos, faz com que seja comum conceber o ténis de mesa como um desporto de oposição, acíclico, balístico, de situação $(12,16,21,23)$. Este conjunto de aspectos faz com que o ténis de mesa seja, nos seus elementos estruturais, um desporto que exige competências técnicas e estratégicas muito bem desenvolvidas.

Séve (23) refere que no ténis de mesa tem de se desenvolver uma motricidade pouco usual, associada à realização com precisão de gestos complexos. Hudetz (11) chama a atenção para o facto de na técnica do ténis de mesa serem englobados a execução de golpes e os deslocamentos necessários para os realizar, formando um todo orgânico.

As estruturas gestuais básicas não constituem modelos a reproduzir, mas correspondem às invariantes do movimento. Neste sentido, o ensino não deve visar a reprodução de formas gestuais formais, antes deve privilegiar os princípios biomecânicos de base (7). No 
ténis de mesa a base do sucesso repousa, pois, sobre a execução do melhor golpe no instante adequado. No plano táctico existem oito factores-chave (26) que devem ser considerados no ténis de mesa: força, velocidade, rotação, colocação, trajectória, direcção, ritmo e variação. Na mesma linha, Erb (4) lembra que o ténis de mesa é um desporto táctico que repousa sobre vários duelos, cujo objectivo é romper o equilíbrio de forças, intervindo sobre os factores referidos por $\mathrm{Wu}$ (26). Por sua vez o equilíbrio/desequilíbrio de forças é o resultado de três outros duelos: (i) Gestão do previsto/imprevisto (certeza/incerteza); (ii) Encadeamento/ruptura (encadear golpes segundo um plano de jogo/provocar rupturas na ligação); e (iii) Segurança de jogo/risco.

No plano fisiológico, o ténis de mesa é caracterizado (5) por uma predominância energética do sistema anaeróbio aláctico, que proporciona um fornecimento rápido de energia ao atleta, caracterizando-se pela velocidade de execução e pela potência dos golpes. $\mathrm{O}$ sistema anaeróbio láctico, ao contrário, está presente na modalidade apenas em jogadas com duração prolongada. A duração das partidas, que varia entre os dez e os vinte e cinco minutos, implica também uma componente metabólica aeróbia. A duração da actividade e a intermitência entre esforço e pausa exigem do jogador de ténis de mesa um condicionamento físico que associe os sistemas anaeróbio aláctico e aeróbio (20). De um ponto de vista psicológico as exigências são grandes. As variáveis a que um atleta está sujeito são tantas que o colocam perante situações muito complexas, uma vez que nunca se sabe como, quando e onde vai chegar a bola. Isto mesmo é enfatizado por Vilani et al (24) ao referirem que se analisarmos medidas físicas como o tempo, o espaço, a velocidade e a aceleração, e encontrarmos a relação entre estas medidas e, por exemplo, a superfície da mesa (fricção, elasticidade, altura e tipo de superfície), podemos observar uma situação extremamente crítica, em que a atenção a certos estímulos e a concentração do jogador durante o jogo são factores essenciais para o êxito.

\section{MATERIAL E MÉTODOS}

Neste estudo, uma vez que se pretendeu observar, registar e analisar factos ou fenómenos sem a intenção de os manipular, optou-se por uma metodologia de carácter descritivo. Mais especificamente, e tendo em conta a forma como Cervo e Bervian (2) definem os diferentes tipos de pesquisas descritivas, considerase que se trata de um estudo exploratório-descritivo. A técnica de pesquisa adoptada foi a análise documental (22), que nos permitiu caracterizar a estrutura e os conteúdos do treino a partir de documentos não elaborados especificamente para fins de investigação.

\section{Amostra}

Foram objecto de análise os dossiers relativos à época de 2002/2003 dos três centros de treino da Federação Portuguesa de Ténis de Mesa. Os documentos de treino analisados constituem 739 unidades de treino correspondentes a 1641 horas de treino, distribuídas da seguinte forma: Centro de Treino de Bragança - 221 unidades, 529 horas; Centro de Treino de Madeira - 288 unidades, 576 horas; Centro de Treino do Porto - 230 unidades, 534 horas.

Esses dossiers incluíam os planos de treino de 32 jovens atletas - crianças e adolescentes com idades compreendidas entre os 10 e os 15 anos - dos Centros de Treino da Federação Portuguesa de Ténis de Mesa em Bragança (11 atletas), Madeira (6 atletas) e Porto (15 atletas), que integravam a chamada Etapa de Especialização de Base do Programa de Preparação Desportiva para o Alto Rendimento. Destes 32 atletas, 14 são internacionais na classe de cadetes (atletas com menos de 15 anos) e integram ainda o projecto de detecção e aperfeiçoamento de talentos da Federação Portuguesa de Ténis de Mesa. A razão da escolha desta amostra prende-se directamente com o problema definido, uma vez que se considera que os jovens que integram estes centros de treino são uma parte representativa dos atletas que integraram recentemente, ou poderão vir a integrar, as selecções nacionais das classes de jovens. Por outras palavras, julgamos que o treino nestes centros é representativo do tipo de treino a que é submetida a "elite jovem nacional".

\section{Categorias do estudo}

Foram definidas quatro grandes categorias, que são factores da performance em qualquer desporto de duelo, como é o caso do ténis de mesa. Essas categorias reportam-se à natureza do treino (técnico, tácti- 
co, físico e psicológico). A estas quatro categorias, acrescentou-se uma quinta - aquecimento/final de sessão - por forma a estabelecer coerência entre o tempo efectivo de treino e aquele que é contabilizado para o conjunto das categorias.

Dentro de cada uma destas categorias foram ainda definidas sub-categorias (Quadro 1).

Quadro 1: Categorias e sub-categorias consideradas na análise da estrutura do treino.

\begin{tabular}{|c|c|c|c|}
\hline Treino Técnico & $\begin{array}{l}\text { Treino } \\
\text { Táctico }\end{array}$ & Treino Físico & $\begin{array}{c}\text { Treino } \\
\text { psicológico }\end{array}$ \\
\hline - Golpes & - Tomada & - Força & - \\
\hline técnicos & de & - Velocidade & Concentração \\
\hline - Serviço & iniciativa/ & - Resistência & - Atenção \\
\hline . & Três & aeróbia & - Rotinas \\
\hline Deslocamentos & primeiras & - Resistência & competitivas \\
\hline laterais & bolas & anaeróbia & -Auto \\
\hline$\cdot$ & - Contra a & - Velocidade & confiança \\
\hline Deslocamentos & tomada & de execução & - Formulação \\
\hline em & de & gestual & de objectivos \\
\hline profundidade & iniciativa & - Velocidade & -Auto- \\
\hline - Precisão & - & de & controlo \\
\hline - & Esquema & deslocamento & - \\
\hline Adaptabilidade & de jogo & -Velocidade & Relaxamento \\
\hline & - Jogo & de reacção & \\
\hline
\end{tabular}

\section{Procedimentos estatísticos}

A análise dos dossiers foi efectuada de uma forma exploratória, recorrendo a contagens e frequências que permitem a descrição e comparação das diferentes categorias de análise do conjunto dos centros de treino.

\section{ANÁLISE E DISCUSSÃO DOS RESULTADOS \\ Parâmetros gerais da carga}

O Quadro 2 apresenta-nos os resultados relativos aos parâmetros gerais da carga nos três centros de treino.
Quadro 2 - Valores dos parâmetros gerais da carga nos Centros de Treino.

\begin{tabular}{|c|c|c|c|c|}
\hline & Bragança & Madeira & Porto & $\begin{array}{c}\text { Média } \\
\text { CT's }\end{array}$ \\
\hline \multicolumn{5}{|c|}{$\mathrm{N}^{0}$ Anual de Unidades de } \\
\hline Treino & 221 & 288 & 230 & 246,3 \\
\hline \multicolumn{5}{|c|}{$\mathrm{N}^{\circ}$ Anual de Semanas de } \\
\hline Treino & $4 ?$ & 48 & 46 & 47,0 \\
\hline \multicolumn{5}{|c|}{$\mathrm{N}^{0}$ Médio de Unidades de } \\
\hline Treino por Semana & 4,7 & 6 & 5 & 5,2 \\
\hline \multicolumn{5}{|c|}{ Duração Média de cada } \\
\hline \multicolumn{3}{|c|}{ Sessão de Treino } & 139,3 & \\
\hline \multicolumn{5}{|l|}{ Horas de Treino por } \\
\hline Semana & 11,26 & 12 & 11,61 & 11,62 \\
\hline \multicolumn{5}{|c|}{ Volume Anual de Treino } \\
\hline
\end{tabular}

O número de unidades de treino semanais (5,2 unidades) e o número anual de semanas de treino (47 semanas) estão de acordo com as propostas de alguns especialistas. Martin (13) refere 45 semanas de treino por ano e 4 a 6 unidades por semana, para a fase em que se inserem os atletas deste estudo. $\mathrm{Na}$ mesma linha, Gadal (10) propõe como volume de treino, entre os 11 e os 14 anos, para chegar ao alto nível, 5 a 7 unidades de treino por semana.

O Quadro 3 apresenta-nos valores de referência da carga semanal de treino para estas idades.

Quadro 3 - Número de horas de treino semanal propostas pelos especialistas, comparativamente com os valores registados neste estudo.

\begin{tabular}{lcccc}
\hline & $\begin{array}{c}\text { Carl } \\
{[1993]}\end{array}$ & $\begin{array}{c}\text { Gadal } \\
{[1997)}\end{array}$ & $\begin{array}{c}\text { Martin } \\
{[1999)}\end{array}$ & $\begin{array}{c}\text { Presente } \\
\text { Estudo } \\
{[2004]}\end{array}$ \\
\hline $\begin{array}{l}\text { No Horas de Treino por } \\
\text { Semana }\end{array}$ & 15,2 & $\leq 14$ & 8 a 14 & 11,6 \\
\hline
\end{tabular}

Martin (13) propõe 8 a 14 horas, enquanto Gadal (10) fala num máximo de 14 horas. Num estudo relativo às horas de treino semanal de jovens mesatenistas na primeira fase do treino de alto rendimento, Carl (1993), citado por Martin (13), registou valores médios de 15,2 $\pm 3,6$ horas semanais de treino. O nosso estudo regista um valor médio de horas de treino semanal (11,6 horas) que, embora dentro dos limites atrás referidos, fica bastante aquém dos 
limites máximos preconizados. Se tivermos em conta os valores sugeridos por Platonov (19) - 600 a 800 horas anuais na fase de preparação específica de base, na qual se inserem os atletas deste estudo verificamos que o volume médio anual de treino nos centros de treino da Federação Portuguesa de Ténis de Mesa não é suficiente.

\section{Categorias e sub-categorias de treino}

Não tendo sido encontradas pesquisas ou dados que indiquem com rigor as percentagens ou tempos de treino relativos a cada uma das categorias definidas, recorreu-se a indicadores baseados nas posições de especialistas do treino de jovens. A leitura do quadro 4, permite-nos dizer que os valores apresentados nas categorias treino técnico, treino táctico, treino físico, parecem estar de acordo com as necessidades referidas por diversos autores para estas idades $(6,9,13,14,25)$.

Quadro 4 - Volume e percentagem anual de treino por categorias nos 3 centros de treino e valores médios.

\begin{tabular}{|c|c|c|c|c|c|c|c|c|}
\hline \multirow[b]{2}{*}{ Categorias } & \multicolumn{2}{|c|}{ Bragança } & \multicolumn{2}{|c|}{ Madeira } & \multicolumn{2}{|c|}{ Porto } & \multicolumn{2}{|c|}{ Média CT's } \\
\hline & (h/ano) & [\%] & (h/ano) & (\%) & (h/ano) & (\%) & (h/ano) & [\%] \\
\hline \multicolumn{9}{|l|}{ Aquecimento/Final } \\
\hline de Sessão & $128,8 ?$ & 24,36 & 144,00 & 25,00 & 134,17 & 25,13 & 135,68 & 24,84 \\
\hline Treino Técnico & 162,22 & 30,66 & 159,57 & 27,70 & 154,32 & 28,91 & 158,70 & 29,05 \\
\hline Treino Táctico & 167,63 & 31,69 & 95,23 & 16,53 & 149,50 & 28,01 & 137,46 & 25,16 \\
\hline Treino Fisico & 70,32 & 13,29 & 153,20 & 26,60 & 95,83 & 17,95 & 106,45 & 19,49 \\
\hline Treino Psicológico & 0 & 0,00 & 24,00 & $4,1 ?$ & 0 & 0,00 & 8,00 & 1,46 \\
\hline Totais & 529,03 & & 576 & & 533,82 & & 546,28 & \\
\hline
\end{tabular}

O quadro 5 permite-nos uma leitura mais detalhada das sub-categorias do treino técnico.

Quadro 5 - Distribuição do volume e percentagem das subcategorias do Treino Técnico reportadas ao Volume Anual Total do Treino.

\begin{tabular}{|c|c|c|c|c|c|c|c|c|}
\hline \multirow[b]{2}{*}{ Treino Técnico } & \multicolumn{2}{|c|}{ Bragança } & \multicolumn{2}{|c|}{ Madeira } & \multicolumn{2}{|c|}{ Porto } & \multicolumn{2}{|c|}{ Média CT's } \\
\hline & [h/ano] & [\%] & [h/ano] & [\%] & [h/ano] & {$[\%]$} & [h/ano] & (\%) \\
\hline \multicolumn{9}{|l|}{ Golpes } \\
\hline Técnicos & 66,30 & 12,53 & 65,15 & 11,31 & 26,83 & 5,03 & 52,76 & 9,62 \\
\hline Serviço & 18,42 & 3,48 & 14,63 & 2,54 & 15,00 & 2,81 & 16,02 & 2,94 \\
\hline \multicolumn{9}{|l|}{ Deslocamentos } \\
\hline laterais & 77,50 & 14,65 & 24,25 & 12,89 & $76,6 ?$ & 14,36 & 76,14 & 13,97 \\
\hline \multicolumn{9}{|l|}{ Deslocamentos } \\
\hline profundidade & 0 & 0,00 & 3,33 & 0,58 & 11,50 & 2,15 & 4,95 & 0,91 \\
\hline Precisão & 0 & 0,00 & 2,22 & 0,38 & 1,32 & 0,25 & 1,18 & 0,22 \\
\hline Adaptabilidade & 0 & 0,00 & 0 & 0,00 & 3,83 & 0,72 & 1,28 & 0,23 \\
\hline \multicolumn{9}{|l|}{ Técnica } \\
\hline [Multibolas] & 0 & 0,00 & 0 & 0,00 & 0 & 0,00 & 0,00 & 0,00 \\
\hline \multicolumn{9}{|l|}{ Adaptabilidade/ } \\
\hline [Multibolas) & 0 & 0,00 & 0 & 0,00 & $19,1 ?$ & 3,59 & 6,39 & 1,17 \\
\hline \multicolumn{9}{|l|}{ Volume Anual } \\
\hline
\end{tabular}

Verifica-se que aos "Deslocamentos Laterais" é atribuída uma expressiva percentagem de treino (14\% 76 horas/ano), o que está de acordo com a sua importância no jogo actual. Já no que diz respeito aos "Deslocamentos em Profundidade", os valores médios anuais são muito inferiores ( $1 \%$ - 5 horas/ano), o que, tendo em atenção os valores encontrados por Djokic (3), é manifestamente inferior ao desejável, uma vez que, em cada jogo, os "Deslocamentos em Profundidade" são cerca de metade dos "Deslocamentos Laterais". Por outro lado, e tendo em atenção as fases sensíveis de aprendizagem, Martin (13) diz que a orientação espacial tem um período óptimo de desenvolvimento entre os 12 e os 15 anos, o que justifica a importância do treino dos deslocamentos.

Em relação ao treino do "Serviço", os seus valores médios anuais situam-se nos 3\% (16 horas/ano). Não correspondem, por isso, à relevância que as características do ténis de mesa actual lhe conferem $(1,6,8,23,26)$.

As restantes subcategorias - "Precisão" e "Adaptabilidade" - apresentam valores muito pequenos $(0,2 \%$ - 1 hora/ano e $1,4 \%$ - 8 horas/ano, respectivamente). Com efeito, reportando-nos ao treino da precisão, o seu interesse é reconhecido por vários especialistas $(8,10,15,23)$. Relativamente à subcategoria "Adaptabilidade", Séve (23) refere que a actividade do jogador de ténis de mesa, numa interacção competitiva, tem componentes que incluem a exploração, o disfarce e a indeterminação, concluindo que, assim sendo, o programa de treino diário deverá ter uma forte componente de exploração e disfarce. Neste sentido, os valores encontrados nestas duas subcategorias estão longe do desejável.

O quadro 6 remete-nos para uma leitura mais detalhada das sub-categorias do Treino Táctico. 
Quadro 6 - Distribuição do volume e percentagem das subcategorias do Treino Táctico reportadas ao Volume Anual Total do Treino.

\begin{tabular}{|c|c|c|c|c|c|c|c|c|}
\hline \multirow{2}{*}{$\begin{array}{l}\text { Treino } \\
\text { Táctico } \\
\end{array}$} & \multicolumn{2}{|c|}{ Bragança } & \multicolumn{2}{|c|}{ Madeira } & \multicolumn{2}{|c|}{ Porto } & \multicolumn{2}{|c|}{ Média CT's } \\
\hline & (h/ano) & $(\%)$ & (h/ano) & {$[\%]$} & (h/ano) & [\%] & (h/ano) & [\%] \\
\hline $\begin{array}{l}\text { Três } \\
\text { primeiras } \\
\text { bolas/ } \\
\text { tomada de }\end{array}$ & & & & & & & & \\
\hline iniciativa & 37,6 & 7,11 & 24,12 & 4,19 & 15,33 & $2,8 ?$ & 25,68 & 4,70 \\
\hline $\begin{array}{l}\text { Contra a } \\
\text { tomada de }\end{array}$ & & & & & & & & \\
\hline iniciativa & 18,8 & 3,55 & 4,45 & 0,77 & 19,17 & 3,59 & 14,14 & 2,59 \\
\hline $\begin{array}{l}\text { Esquemas } \\
\text { de jogo }\end{array}$ & 29,77 & 5,63 & 13,33 & 2,31 & 15,33 & $2,8 ?$ & 19,48 & $3,5 ?$ \\
\hline Jogo & $81,4 ?$ & 15,40 & 53,33 & 9,26 & $99,6 ?$ & $18,6 ?$ & 78,16 & 14,31 \\
\hline $\begin{array}{l}\text { Volume } \\
\text { Anual de }\end{array}$ & & & & & & & & \\
\hline Treino & 529,03 & & 576 & & 533,82 & & 546,28 & \\
\hline
\end{tabular}

Destaca-se, neste quadro, o tempo de treino dedicado à subcategoria "Jogo" (cerca de 14\% - 78,1 horas/ano em média), muito superior ao tempo dedicado às restantes subcategorias.

Os valores encontrados neste estudo para as "Três Primeiras Bolas/Tomada de Iniciativa" (4,7\% - 26 horas/ano) parecem estar de acordo com o que se considera ser necessário no trabalho táctico em Ténis de Mesa.

Se as três primeiras bolas ganham relevância, e se se desenvolve a tomada de iniciativa o mais cedo possível, através do aperfeiçoamento do golpe terminal/golpe forte, estes factos têm como consequência a exigência dos atletas dominarem, também, o jogo "Contra a Tomada de Iniciativa". Considera-se assim que os valores registados relativamente à "Contra-Tomada de Iniciativa" (2,6\% - 14,1 horas/ano) parecem ser insuficientes. Relativamente às duas últimas subcategorias "Esquema de Jogo" e "Jogo" - os números aqui registados vão ao encontro do que são as necessidades do treino do ténis de mesa nestas idades. O quadro 7 reporta-se às sub-categorias do Treino Físico.
Quadro 7 - Distribuição do volume e percentagem das subcategorias do Treino Físico reportadas ao Volume Anual Total do Treino.

\begin{tabular}{|c|c|c|c|c|c|c|c|c|}
\hline \multirow[b]{2}{*}{ Treino Físico } & \multicolumn{2}{|c|}{ Bragança } & \multicolumn{2}{|c|}{ Madeira } & \multicolumn{2}{|c|}{ Porto } & \multicolumn{2}{|c|}{ Média CT's } \\
\hline & [h/ano] & $(\%)$ & [h/ano] & {$[\%]$} & (h/ano) & {$[\%]$} & [h/ano] & (\%) \\
\hline Força & 2,95 & 0,56 & 12,00 & 2,08 & 0 & 0,00 & 4,98 & 0,91 \\
\hline Velocidade & 3,13 & 0,59 & 12,00 & 2,08 & 0 & 0,00 & 5,04 & 0,92 \\
\hline \multicolumn{9}{|l|}{ Resistência } \\
\hline aeróbia & 2,35 & 0,44 & 12,00 & 2,08 & 0 & 0,00 & 4,78 & 0,88 \\
\hline \multicolumn{9}{|l|}{ Resistência } \\
\hline anaeróbia & 3,13 & 0,59 & 12,00 & 2,08 & 0 & 0,00 & 5,04 & 0,92 \\
\hline \multicolumn{9}{|l|}{ Velocidade } \\
\hline \multicolumn{9}{|l|}{ execução } \\
\hline \multicolumn{9}{|l|}{ gestual } \\
\hline [Multibolas] & 0 & 0,00 & $16,0 ?$ & 2,79 & 0 & 0,00 & 5,36 & 0,98 \\
\hline \multicolumn{9}{|l|}{ Velocidade de } \\
\hline \multicolumn{9}{|l|}{ reacção } \\
\hline [Multibolas] & 36,82 & 6,96 & 36,23 & 6,29 & 35,07 & $6,5 ?$ & 36,04 & 6,60 \\
\hline \multicolumn{9}{|l|}{$\begin{array}{l}\text { Velocidade de } \\
\text { deslocamento }\end{array}$} \\
\hline (Multibolas) & 21,93 & 4,15 & 52,9 & 9,18 & 60,77 & 11,38 & 45,20 & 8,27 \\
\hline \multicolumn{9}{|l|}{ Volume Anual } \\
\hline de Treino & 529,03 & & 576 & & 533,82 & & 546,28 & \\
\hline
\end{tabular}

A "Velocidade", em particular a "Velocidade de Reacção" (36 horas/ano - cerca de 7\%) e a "Velocidade de Deslocamentos" (45,2 horas/ano cerca de $8 \%$ ), ocupa um papel nuclear no treino dos jovens mesatenistas deste estudo.

Esta capacidade motora é, como vimos, uma das mais importantes no jogo do ténis de mesa moderno. Verificamos, no quadro, que ao conjunto das subcategorias relativas à velocidade é dedicado um tempo significativo (cerca de $17 \%$ do volume anual de treino). As várias formas de manifestação da velocidade aqui apresentadas são, obviamente, também treinadas noutro tipo de situações - como por exemplo o jogo, esquemas de jogo, tomada de iniciativa, etc. - o que vem reforçar a ideia de que o tempo dedicado a esta componente é compatível com a importância do jogo evoluído.

Analisando o quadro, verifica-se que a média do tempo de treino da "Força" é residual (5horas/ano cerca de $1 \%$ ), o que não atende à importância do treino da mesma referida pelos especialistas, em particular nas idades mais avançadas do intervalo. Os valores relativos ao treino das subcategorias "Resistência Anaeróbia" e "Resistência Aeróbia", sendo residuais, não parecem estar de acordo com o quadro estabelecido pelos especialistas.

O quadro 8 , finalmente, reporta-se às sub-categorias do Treino Psicológico. 
Quadro 8: Distribuição do volume e percentagem das subcategorias do Treino Psicológico reportadas ao Volume Anual Total do Treino.

\begin{tabular}{|c|c|c|c|c|c|c|c|c|}
\hline \multirow{2}{*}{$\begin{array}{l}\text { Treino } \\
\text { Psicológico }\end{array}$} & \multicolumn{2}{|c|}{ Bragança } & \multicolumn{2}{|c|}{ Madeira } & \multicolumn{2}{|c|}{ Porto } & \multicolumn{2}{|c|}{ Média CT's } \\
\hline & [h/ano] & (\%) & (h/ano) & $(\%)$ & (h/ano) & (\%) & [h/ano] & {$[\%]$} \\
\hline Concentração & 0 & 0,00 & 0 & 0,00 & 0 & 0,00 & 0 & 0,00 \\
\hline Atenção & 0 & 0,00 & 0 & 0,00 & 0 & 0,00 & 0 & 0,00 \\
\hline \multicolumn{9}{|l|}{ Rotinas } \\
\hline Competitivas & 0 & 0,00 & 0 & 0,00 & 0 & 0,00 & 0 & 0,00 \\
\hline Auto-confiança & 0 & 0,00 & 0 & 0,00 & 0 & 0,00 & 0 & 0,00 \\
\hline \multicolumn{9}{|l|}{ Formulação de } \\
\hline Objectivos & 0 & 0,00 & 8,5 & 1,48 & 0 & 0,00 & 2,83 & 0,52 \\
\hline Auto-controlo & 0 & 0,00 & 7,5 & 1,30 & 0 & 0,00 & 2,5 & 0,46 \\
\hline Relaxação & 0 & 0,00 & 8 & 1,39 & 0 & 0,00 & 2,67 & 0,49 \\
\hline $\begin{array}{l}\text { Volume Anual } \\
\text { de Treino }\end{array}$ & 529,03 & & 576 & & 533,82 & & 546,3 & \\
\hline
\end{tabular}

Da análise do Quadro 8, verifica-se que apenas as subcategorias "Formulação de Objectivos", "Autocontrolo" e "Relaxação" são alvo de treino, e mesmo estas somente no Centro da Madeira.

De entre as categorias definidas neste estudo, os valores registados na categoria Treino Psicológico são aqueles que estão mais aquém (sendo mesmo, na maior parte dos casos, inexistentes) do que é indicado pelos peritos. O treino psicológico envolve processos contínuos e demorados que carecem de volumes de treino superiores aos registados neste estudo.

\section{CONCLUSÕES}

Sendo este um primeiro estudo sobre o Ténis de Mesa em Portugal, espera-se que ele possa servir de referência para estudos futuros e contribuir, assim, para aprofundar a resposta a problemas que o presente estudo não esgota.

Os resultados deste estudo permitem concluir que:

- O número anual de semanas de actividade nos Centros de Treino da Federação Portuguesa de Ténis de Mesa ultrapassa os valores de referência preconizados pelos especialistas, mas os valores do volume anual de treino não são suficientes para a obtenção das melhores performances na idade adulta. No que diz respeito ao número de unidades de treino semanais e ao número de horas de treino por semana, os valores encontrados estão aquém dos números máximos sugeridos pelos especialistas.

- Quanto à distribuição do treino pelas categorias definidas no presente estudo, a ênfase é colocada no treino técnico e táctico, de acordo aliás com as características do ténis de mesa e com as recomendações dos especialistas. O facto do treino físico ser inferior pode não significar contudo desconsideração pelo mesmo, uma vez que, como é sabido, ele pode ser treinado de forma integrada com o treino técnico e o treino táctico. No que diz respeito à componente psicológica, e tendo em atenção a relevância que lhe é atribuída no ténis de mesa actual, é notória a lacuna no treino deste elemento.

- A análise das subcategorias do treino permite detectar falhas que poderão contribuir para obstar à realização de bons resultados na idade adulta e que, por isso, merecem ser sublinhadas. Analisando as subcategorias do treino técnico, conclui-se que parece ser insuficiente o tempo dedicado às subcategorias "Serviço", "Deslocamentos em Profundidade", "Precisão" e "Adaptabilidade", cujo treino está muito longe da importância que estes parâmetros evidenciam no ténis de mesa moderno. No que se refere às subcategorias do treino táctico, o tempo de treino dedicado à subcategoria "Contra a Tomada de Iniciativa" não está de acordo com as necessidades actuais, tendo em atenção a intencionalidade atacante que marca o ténis de mesa contemporâneo. No que se refere às subcategorias do treino físico, conclui-se que os valores registados ficam a dever-se fundamentalmente ao treino da velocidade com recurso ao treino com multibolas. No que se refere ao treino "fora da mesa" das quatro grandes componentes (força, velocidade, resistência aeróbia e resistência anaeróbia), os tempos encontrados são pouco significativos e não estão de acordo com as necessidades da modalidade. No que se refere ao treino psicológico, subcategorias como a "Concentração" e a "Atenção", dimensões incontornáveis em desportos com as características do ténis de mesa (situacional/duelo), são completamente desvalorizadas.

\section{CORRESPONDÊNCIA}

\section{Fernando Augusto Pacheco Malheiro}

Rua Fernanda Ribeiro, 246

4560-294 Novelas

Penafiel - Portugal

fmalheiro@clix.pt 


\section{BIBLIOGRAFIA}

1. Cai, H.; Tang (2002). A comparison of the table tennis capabilities of Sweden in the past century. In N. Yuza (Ed.) Table tennis sciences $\mathrm{n}^{\circ} 4$ \& 5. Lausanne: International Table Tennis Federation, 68-73.

2. Cervo, A.; Bervian, P. (1983). Metodologia científica para uso dos estudantes universitários. S. Paulo: McGraw-Hill.

3. Djokic, Z. (2003). Basic and special physical preparation of top table tennis players. Comunicação apresentada ao VIII Congresso da I.T.T.F. e III Congresso de Ciências do Desporto (Desportos de Raquete). Paris, 17 a 19 de Maio.

4. Erb, G. (1993). Le tennis de table. Paris: Amphora.

5. Faccini, P. ; Faina, M. ; Scarpellini, E.; Dal Monte, A. (1989). Il costo energético nel tennistavolo. Scuola dello sport $8,38-42$.

6. Fédération Française de Tennis de Table (1992). Technique du tennis de table. Montrouge: Editions France Tennis de Table.

7. Fédération Française de Tennis de Table (1998). La méthode française. Montrouge : Editions France Tennis de Table

8. Fédération Française de Tennis de Table (2003). Au top du top. Montrouge: Savoir Gagner.

9. Filin, V. (1996). Desporto Juvenil - Teoria e Metodologia. Londrina, Pr: CID.

10. Gadal, M. (1997). Train to win, learn and teach top level table tennis. Ottawa: Edição de autor.

11. Hudetz, R (1988). Stolni tenis tehnka. Zagreb: Sportska Tribina.

12. Mari, J (1997). Programa de entrenamiento psicológico para jugadores de tenis de mesa de alto nível. Revista de Psicologia del Deporte, 12, 77-88.

13. Martin, D. (1999). Capacidade de performance e desenvolvimento no desporto de jovens. In Comunicações do Seminário Internacional Treino de Jovens 1998. Lisboa: Secretaria de Estado do Desporto. Centro de Estudos e Formação Desportiva, 31-59.

14. Mateveev, L. (2001). Teoria General del Entrenamiento Deportivo. Barcelona: Editorial Paidotribo.

15. Molodzoff, P. (1993). Planification dans les CPEF. École Féderal des Cadres, Université d 'Été 25 au 29 juillet de la Fédération Francaise de Tennis de Table.

16. Moreno, J. (1994). Fundamentos del deporte. Análisis de las estructuras del juego deportivo. Barcelona: Inde Publicaciones.

17. Otcheva, G.; Drianovski, Y. (2002). Comparative analyses of the games of the finalists from de biggest international and bulgarian table tennis competitions in 2000. In N. Yuza (Ed.). Table tennis sciences $n^{\circ} 4 \& 5$. Lausanne: International Table Tennis Federation, 155-166.

18. Ouyang, J.; Wu, T. (2003). The optimal training techniques for players at elementary school stage. Comunicação apresentada ao VIII Congresso da I.T.T.F. e III Congresso de Ciências do Desporto (Desportos de Raquete). Paris, 17 a 19 de Maio.

19. Platonov, V. (1994). Il Principi della preparazione a lungo termine. Sds/Rivista di Cultura Sportiva 51, 2-11.

20. Reilley, T.; Secher, N.; Snell, P. e Williams, C. (1990). Physiology of sports. London: E.\& F. N. Spon.

21. Riera, J. (1985). Introdução à psicologia desporto. Barcelona: Martinez Roca.

22. Schnabel G, Gutewort W, Hirtz P, Klimpel P. (1987). Methoden zur Gewinnung empirischen Wissens. Wissenschaftliche Zeitschrift der DHfK 28, Sonderheft 3: 181-230.
23. Séve, C. (2000). Le tennis de table, entraînement et compétition. Montrouge: Fédération Française de Tennis de Table.

24. Vilani, L.; Samulski, D. e Lima, F. (2003). Aspectos generales de la atencion y la concentracion en el ténis de mesa. Comunicação apresentada no Congresso Científico Internacional Aplicado al Ténis de Mesa, 17 de Dezembro de 2003. Santiago do Chile. Disponível em: http://www.ittf_com/Abstracts-Spanish1.pdf

25. Weineck, J. (1983): Manuel d'entraînement. Paris: Editions Vigot.

26. Wu, T. (2003). A study on characteristics of table tennis. Comunicação apresentada ao VII Congresso da I.T.T.F. e II Congresso de Ciências do Desporto (Desportos de Raquete). Osaka, 21 a 23 de Abril. 